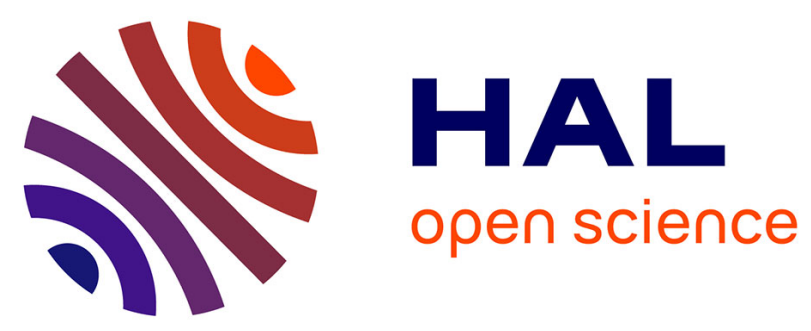

\title{
Effects of Exposure to a 128-mT Static Magnetic Field on Glucose and Lipid Metabolism in Serum and Skeletal Muscle of Rats
}

Miryam Elferchichi, Jacques Mercier, Marjorie Coisy-Quivy, Lore Metz, Anne-Dominique Lajoix, René Gross, Hatem Belguith, Hafedh Abdelmelek, Mohsen Sakly, Karen Lambert

\section{To cite this version:}

Miryam Elferchichi, Jacques Mercier, Marjorie Coisy-Quivy, Lore Metz, Anne-Dominique Lajoix, et al.. Effects of Exposure to a 128-mT Static Magnetic Field on Glucose and Lipid Metabolism in Serum and Skeletal Muscle of Rats. Archives of Medical Research, 2010, 41 (5), pp.309-314. 10.1016/j.arcmed.2010.07.008 . hal-02540647

\section{HAL Id: hal-02540647 \\ https://hal.umontpellier.fr/hal-02540647}

Submitted on 11 Apr 2020

HAL is a multi-disciplinary open access archive for the deposit and dissemination of scientific research documents, whether they are published or not. The documents may come from teaching and research institutions in France or abroad, or from public or private research centers.
L'archive ouverte pluridisciplinaire HAL, est destinée au dépôt et à la diffusion de documents scientifiques de niveau recherche, publiés ou non, émanant des établissements d'enseignement et de recherche français ou étrangers, des laboratoires publics ou privés. 


\title{
Effects of Exposure to a 128-mT Static Magnetic Field on Glucose and Lipid Metabolism in Serum and Skeletal Muscle of Rats
}

\author{
Miryam Elferchichi, ${ }^{\text {a,b,c }}$ Jacques Mercier, ${ }^{\text {b,c }}$ Marjorie Coisy-Quivy, ${ }^{\mathrm{b}}$ Lore Metz, ${ }^{\mathrm{d}}$ \\ Anne-Dominique Lajoix, ${ }^{\mathrm{e}}$ Rene Gross, ${ }^{\mathrm{e}}$ Hatem Belguith, ${ }^{\mathrm{a}}$ Hafedh Abdelmelek, ${ }^{\mathrm{a}}$ Mohsen Sakly, ${ }^{\mathrm{a}}$ \\ and Karen Lambert ${ }^{\mathrm{b}, \mathrm{c}}$ \\ ${ }^{a}$ Faculté des Sciences de Bizerte, Laboratoire de Physiologie Intégrée, Jarzouna, Tunisia \\ bINSERM, ERI25, Muscle and Pathologies, Montpellier, France \\ ${ }^{\mathrm{c}}$ Université Montpellier I, Montpellier, France \\ ${ }^{\mathrm{d}}$ Laboratoire de Biologie des Activités Physiques et Sportives, Biologie Bat B, Universite Blaise Pascal, Les Cézeaux, Aubière, France \\ ${ }^{\mathrm{e}}$ CNRS UMR5232, UM1, Centre for Pharmacology and Innovation in Diabetes, Montpellier, France
}

\begin{abstract}
Background and Aims. Increasing environmental pollution may participate in the growing incidence of metabolic disorders. Static magnetic fields (SMFs) are an emerging environmental health issue due to increased exposure in residential and commercial areas; however, their metabolic effects in serum and skeletal muscle are largely unknown. The aim of this study was to investigate the effect of SMF exposure on glucose and lipid metabolism in serum and skeletal muscles of rats.

Methods. Twelve 6- to 7-week-old male Wistar rats were randomly divided into two groups: rats exposed to $128 \mathrm{mT} \mathrm{SMF}$ and sham-exposed rats. This moderate-intensity exposure was performed for $1 \mathrm{~h}$ /day for 15 consecutive days.

Results. Animals exposed to $128 \mathrm{mT}$ SMF displayed significant changes in both glucose (i.e., increases in plasma glucose and lactate and decrease in plasma insulin levels) and lipid (i.e., increases in plasma glycerol, cholesterol and phospholipids but not triglyceride levels) metabolism. During intraperitoneal glucose tolerance tests, SMF-exposed rats displayed significantly higher hyperglycemia compared to sham-exposed rats despite similar insulin levels in both groups. In tissues, SMF exposure induced significant alterations in enzyme activities only in glycolytic muscles and caused a significant decrease in quadriceps and liver glycogen content together with increased phospholipid levels.

Conclusions. This study provides evidence that subacute SMF exposure of moderate intensity induces important alterations of glucose and lipid metabolisms, which deserve further investigations to evaluate long-term consequences.
\end{abstract}

Key Words: Metabolism, Skeletal muscle, Static magnetic fields.

\section{Introduction}

The incidence of metabolic disorders grows among developing nations. Several factors are known to promote metabolic alterations. These include endogenous factors characterized by the interplay of genes with insulin-related abnormalities

\footnotetext{
Address reprint requests to: Karen Lambert, INSERM ERI25, Bâtimen Crastes de Paulet, Hôpital A. de Villeneuve, 34295 Montpellier Cedex 5 France; Phone: + 33(4) 674152 30; FAX: + 33(4) 674152 31; E-mail: karen.lambert@univ-montp1.fr
}

and metabolic deregulations, as well as exogenous factors such as sedentary life style, food intake and environmental exposure $(1-3)$.

This latter factor may be implicated in the development of metabolic disorders $(1,2,4)$. Electromagnetic fields (EMFs) and static magnetic fields (SMFs) are growing environmental pollutants due to increased exposure in both residential and working areas $(5,6)$. To date there are few data on health effects of static magnetic fields.

In an attempt to address the biological effects of SMFs, it is useful to classify them as weak $(<1 \mathrm{mT})$, moderate 
( $1 \mathrm{mT}$ to $1 \mathrm{~T})$, strong $(1-5 \mathrm{~T})$ and ultrastrong $(>5 \mathrm{~T})$. Until recently, the International Commission on Non-Ionizing Radiation Protection (ICNIRP) recommendations for occupational exposure were a whole-working-day timeaveraged exposure limit of $200 \mathrm{mT}$. The acute exposure limit for head and trunk was $2 \mathrm{~T}$, which is the maximum for limiting vertigo, nausea and metallic taste (7). In 2009, SMF guidelines were modified (8). Now, the public limit is at $400 \mathrm{mT}$ for occupational exposure and up to $8 \mathrm{~T}$ exposure can be permitted in a controlled environment. However, moderate-intensity SMF exposure (generally $\sim 200 \mathrm{mT}$ ) has been shown to affect a wide variety of biological systems in vitro (9-15). Another important and so far underestimated outcome is the impact of SMFs on in vivo metabolism. Indeed, the most recently published study deals with the effects of SMFs on bacteria metabolism (16) and only few studies describe their effects in mammals. For instance, Gorczynska et al. (17) observed an increase in blood glucose associated with a reduced insulin secretion in rats exposed to a constant magnetic field of moderate intensity, $1 \mathrm{~h}$ /day for 10 days. Recently, Chater et al. (18) reported an increase in glycemia after subacute exposure of pregnant rats to $128 \mathrm{mT}, 1 \mathrm{~h}$ /day for 13 consecutive days.

Skeletal muscles represent the most important metabolically active mass of the body and play a major role in the regulation of lipid and glucose metabolism. Therefore, skeletal muscles may be sensitive to SMF exposure. Metabolic response is highly dependent on oxidative and glycolytic muscle fiber types with sensitivity to external stimuli related to muscle typology (3). In vitro, SMFs enhance skeletal muscle differentiation (19) and accelerate $\mathrm{Ca}^{2+}$ / calmodulin-dependent myosin light-chain phosphorylation (20). Moreover, SMFs alter ion transporters (9) and seem to affect muscle microcirculation $(14,21,22)$. Finally, because SMFs are widely used in therapeutics for musculoskeletal pain relief (23), it is crucial to dissect their effect on skeletal muscle homeostasis and to take into account muscle typology.

In the present study, our aim was to investigate whether subacute exposure to moderate-intensity SMFs could induce both systemic and local (i.e., in oxidative and glycolytic muscle and liver) alterations of glucose and lipid metabolism. Therefore, we compared various hormonal and metabolic parameters in male Wistar rats exposed or not to $128 \mathrm{mT}$ $\mathrm{SMF}$ (1 h/day) for 15 days.

\section{Materials and Methods}

\section{Animals and Protocol}

Animal care and experimental procedures were carried out in accordance with the guidelines set by the European Community Directives (86/609/EEC) and the protocol was approved by the Ethics Committee of the University of Montpellier I, France.
Twelve 6- to 7-week-old male Wistar rats were housed ( $n=3 /$ cage) in a temperature-controlled room at $25^{\circ} \mathrm{C}$ with a relative humidity of $80 \%$ and a $12: 12 \mathrm{~h}$ light-dark cycle (lights on at $8 \mathrm{AM}$ ). Water and food were available ad libitum. Rats were randomly divided into two groups: rats exposed to $128 \mathrm{mT} \operatorname{SMF}(n=6, \mathrm{SMF})$ and shamexposed rats $(n=6$, sham exposed). Rats exposed to 128 mT SMF and sham-exposed rats were placed in the electromagnet for $1 \mathrm{~h} /$ day for 15 consecutive days. The exposure period always took place between 8 and 12 AM under standard light exposure and constant temperature.

\section{Exposure System}

We used an electromagnet (Model EM4-HVA, Lake Shore Cryotronic, Inc., Westerville, $\mathrm{OH}$ ) and a magnet power supply (Model 647, Lake Shore Cryotronic, Inc.) with an air gap of $11 \mathrm{~cm}$. This apparatus incorporates watercooled coils and precision yokes that assure precise cap alignment and excellent field stability and uniformity when high power is required to achieve the maximum field capability for the electromagnet. SMF intensity was measured and standardized over the total floor area of the plexiglas cage at $128 \mathrm{mT}$. SMF uniformity in the active exposure volume was $\pm 0.2 \%$ over $1 \mathrm{~cm}^{3}$. The cage measured $20 \times$ $10 \times 20 \mathrm{~cm}$. The two coils of the Lake Shore electromagnet were separated by a $12.1-\mathrm{cm}$ gap. Exposed and shamexposed rats ( $n=2 /$ each time) were placed in the cage at the center of the uniform field area and exposed (or not) to $128 \mathrm{mT} \mathrm{SMF}$.

\section{Intraperitoneal Glucose Tolerance tests (IPGTT)}

Two days before sacrifice, rats underwent an intraperitoneal glucose tolerance test (IPGTT) as previously described (24). Briefly, after being fasted for $4 \mathrm{~h}$, a glucose solution (2 $\mathrm{g} / \mathrm{kg}$ body weight) was administered IP. Blood was collected after tail snipping at time 0 and 20, 40, 60, and 90 min after glucose administration for measurements of plasma glucose and insulin levels.

\section{Blood Chemistry}

Exposed and sham-exposed rats were sacrificed by decapitation in postprandial state. Blood samples were immediately centrifuged and plasma aliquots were frozen and stored at $-80^{\circ} \mathrm{C}$ until assays.

Plasma glucose and glycerol/triglyceride concentrations were determined using enzymatic methods following the manufacturer's instructions (Sigma 510, and Serum Triglycerides Determination Kit TR0100, Sigma, France). Insulin concentrations were determined using radioimmunoassay with ${ }^{125}$ I-labeled insulin and a rat insulin antiserum to determine the level of rat insulin. The sensitivity of this radioimmunoassay was $0.02 \mathrm{ng} / \mathrm{ml}$ (SRI-13K, Labodia, France). The colorimetric enzymatic test CHOD-PAP (Biomaghreb 
20111, Tunisia) was used for cholesterol quantification according to the manufacturer's instructions. Lactate concentration was determined according to the method of Gutmann and Wahlefeld (25) and plasma phospholipids were analyzed following the method developed by Shibuya et al. (26).

\section{Tissue Sampling}

Immediately after sacrifice, the soleus (SOL; oxidative muscle) and the extensor digitorum longus (EDL; glycolytic muscle) of the hindlimb were removed, frozen in liquid nitrogen and stored at $-80^{\circ} \mathrm{C}$ until use for enzymatic activities measurements. Quadriceps and liver biopsies were carried out to be used for determination of tissue glycogen, phospholipids, triglycerides and glycerol concentrations.

\section{Enzymatic Activities}

Citrate synthase (CS) activity was measured at $412 \mathrm{~nm}$ and $30^{\circ} \mathrm{C}$ for $2.5 \mathrm{~min}$ as suggested by Srere (27). 3-Hydroxyacyl-coenzyme A-dehydrogenase (HADH) and lactate dehydrogenase (LDH) activities were measured at $340 \mathrm{~nm}$ for $10 \mathrm{~min}$ and $2.5 \mathrm{~min}$, respectively. Results are expressed in micromoles/minute/g of tissue $(\mu \mathrm{mol} / \mathrm{min} / \mathrm{g})$.

\section{Muscle and Liver Glycogen Contents}

Muscle and liver glycogen contents were determined from quadriceps and liver biopsies using the procedure described by Lo et al. (28). Values were calculated from a standard curve generated at the same time and expressed in $\mathrm{mg}$ glycogen $/ g$ tissue.

\section{Data Presentation and Statistical Analysis}

Data are presented as mean \pm SEM. Statistical significance of the differences between mean values was assessed by Student $t$-test or Mann-Whitney U test; differences within groups for the IPGTT values were assessed by analysis of variance (ANOVA) followed by Bonferroni post hoc tests. The level of significance was set at $p<0.05$.

\section{Results}

\section{Effect of SMF on Body Weight and Metabolic Parameters}

SMF exposure did not induce an obvious phenotype; exposed rats were normal in terms of appearance, body weight and relative weight of tissues. However, SMF-exposed rats displayed significant changes in metabolic parameters. Under postprandial conditions, SMF-exposed rats presented higher glycemia and lower insulinemia values than sham-exposed animals (Table 1). They also displayed a significant increase of plasma lactate compared to sham-exposed rats.
Table 1. Basal metabolic and morphometric parameters in shamexposed and SMF-exposed rats

\begin{tabular}{lcc}
\hline & Sham-exposed rats & SMF-exposed rats \\
\hline Weight $(\mathrm{g})$ & $244.4 \pm 21.4$ & $206.3 \pm 8.4$ \\
Glycemia $(\mathrm{mg} / \mathrm{dL})$ & $166.0 \pm 4.2$ & $205.6 \pm 5.9^{\mathrm{a}}$ \\
Insulin $(\mathrm{ng} / \mathrm{ml})$ & $2.15 \pm 0.46$ & $0.83 \pm 0.13^{\mathrm{b}}$ \\
Lactate $(\mathrm{mM})$ & $1.45 \pm 0.14$ & $3.20 \pm 0.45^{\mathrm{b}}$ \\
Triglycerides (mg/dL) & $66.06 \pm 11.00$ & $47.40 \pm 8.69$ \\
Glycerol $(\mathrm{mg} / \mathrm{dL})$ & $13.99 \pm 2.59$ & $22.61 \pm 5.33^{\mathrm{a}}$ \\
Cholesterol $(\mathrm{g} / \mathrm{l})$ & $0.97 \pm 0.04$ & $1.26 \pm 0.06^{\mathrm{b}}$ \\
Phospholipids $(\mathrm{mg} / \mathrm{ml})$ & $1.04 \pm 0.04$ & $1.64 \pm 0.14^{\mathrm{b}}$ \\
\hline$n=6$ in each group. & \multicolumn{2}{|}{} \\
${ }^{\mathrm{a}} p<0.05$. & \\
${ }^{\mathrm{p}} p<0.01$ significantly different from sham-exposed rats.
\end{tabular}

On the other hand, SMF exposure had no effect on the triglycerides level, whereas it strongly enhanced plasma glycerol, cholesterol and phospholipid concentrations.

\section{Effect of SMF Exposure on Glucose Tolerance}

To investigate whole-body glucose metabolism, IPGTT was performed in fasted animals 2 days before sacrifice. IP administration of glucose resulted in an increase of plasma glucose and insulin concentrations in both groups (Figure 1). However, ANOVA analysis showed that overall, SMF-exposed rats had a significant higher glucose levels than sham-exposed animals $(p<0.01)$. These higher glucose levels in exposed rats were accompanied by insulin levels similar to those observed in non-exposed control animals.
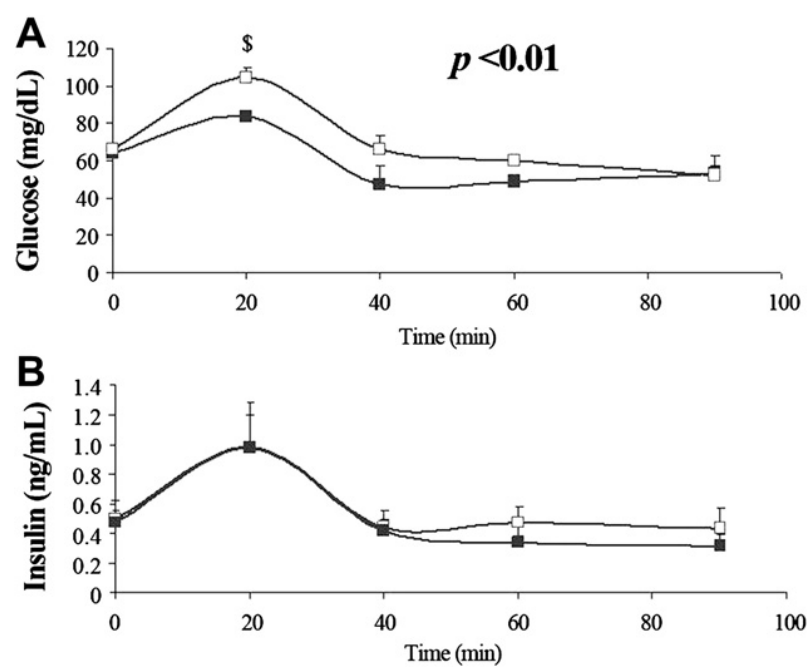

Figure 1. Glucose (A) and insulin (B) levels during an intraperitoneal glucose tolerance test (IPGTT) in sham-exposed $(\boldsymbol{\square} ; n=5)$ and SMF exposed rats $(\square ; n=6)$. Values are mean \pm SEM. There is a significant increase in hyperglycemia in SMF-exposed rat $(p<0.01)$ compared to sham-exposed rat and \$: statistical difference $(p<0.01)$ at time $20 \mathrm{~min}$ between groups. 
Table 2. Liver and quadriceps parameters in sham-exposed and SMF-exposed rats

\begin{tabular}{|c|c|c|c|c|}
\hline & \multicolumn{2}{|c|}{ Liver } & \multicolumn{2}{|c|}{ Quadriceps } \\
\hline & Sham & SMF & Sham & SMF \\
\hline Glycogen (mg/g tissue) & $33.3 \pm 3.1$ & $25.2 \pm 1.4^{\mathrm{a}}$ & $5.7 \pm 0.5$ & $3.2 \pm 0.3^{\mathrm{b}}$ \\
\hline Phospholipids (mg/g tissue) & $16.7 \pm 0.6$ & $20.4 \pm 0.3^{\mathrm{b}}$ & $12.7 \pm 0.7$ & $17.7 \pm 1.2^{\mathrm{b}}$ \\
\hline Triglycerides $(\mathrm{mg} / \mathrm{dL})$ & $98.6 \pm 13.7$ & $110.3 \pm 11.0$ & $20.0 \pm 2.2$ & $22.1 \pm 1.4$ \\
\hline Glycerol (mg/dL) & $103.0 \pm 12.1$ & $117.7 \pm 9.9$ & $19.0 \pm 1.7$ & $20.6 \pm 1.3$ \\
\hline
\end{tabular}

$n=6$ in each group.

${ }^{\mathrm{a}} p<0.05$.

${ }^{\mathrm{b}} p<0.01$ significantly different from sham-exposed rats.

\section{Effects on Metabolic Parameters in Quadriceps and Liver Biopsies after SMF Exposure}

Because skeletal muscle and liver play a crucial role in glucose and lipid metabolism, we then analyzed metabolic parameters in these tissues. Glycogen content was strongly reduced both in quadriceps (by 44\%) and liver (by 25\%) biopsies of exposed rats compared with sham-exposed rats. We also noticed a significant increase in phospholipid content in both tissues after exposure to SMF (Table 2); in contrast, we did not find significant differences in hepatic and muscular levels of triglycerides and glycerol (Table 2).

\section{Enzymatic Activities in Oxidative and Glycolytic Muscle Biopsies after SMF Exposure}

To further analyze the effect of SMF exposure on skeletal muscle, we studied the activities of enzymes involved in glycolytic and oxidative metabolism in both oxidative and glycolytic muscle. We therefore tested CS, HADH and LDH activities in the soleus (SOL; oxidative muscle) and in the extensor digitorum longus (EDL; glycolytic muscle) of both groups (Figure 2). SMF exposure did not affect CS, HADH and LDH activities in oxidative muscles. Conversely, in glycolytic muscles, SMF exposure reduced CS activity and increased LDH but had no effect on HADH activity.

\section{Discussion}

In this study we showed that exposure of normal Wistar rats to $128 \mathrm{mT} \mathrm{SMF} \mathrm{(1} \mathrm{h/day)} \mathrm{for} 15$ days induced significant changes in lipid and glucose homeostasis. In accordance with previously published studies $(17,18)$, we found that rats exposed to SMF displayed significantly higher glycemia and lower insulinemia. We were also able to show that exposure to SMF induced a significant increase in hyperglycemia after IPGTT without insulin response alteration, suggesting a decrease in glucose tolerance possibly due to impaired glucose uptake after SMF exposure. The main tissues implicated in glucose uptake are skeletal muscle and liver. We did find a significant decrease in glycogen content in muscles and liver. This reduction may be caused either by decreased glucose uptake or increased glycogenolysis. Indeed, Abdelmelek et al. (29) reported higher norepinephrine levels in skeletal muscle of rats after SMF exposure at $128 \mathrm{mT}$, which could account for increased glycogen breakdown. Such a hypothesis cannot be excluded but, in our opinion, a decrease in glucose uptake is more likely to be responsible for the reduction of glycogen content in liver and skeletal muscles. Indeed, our exposed rats also presented higher plasma lactate concentrations and several studies have demonstrated a metabolic competition between lactate and glucose uptake $(30,31)$. In the presence of elevated plasma lactate, glucose uptake is
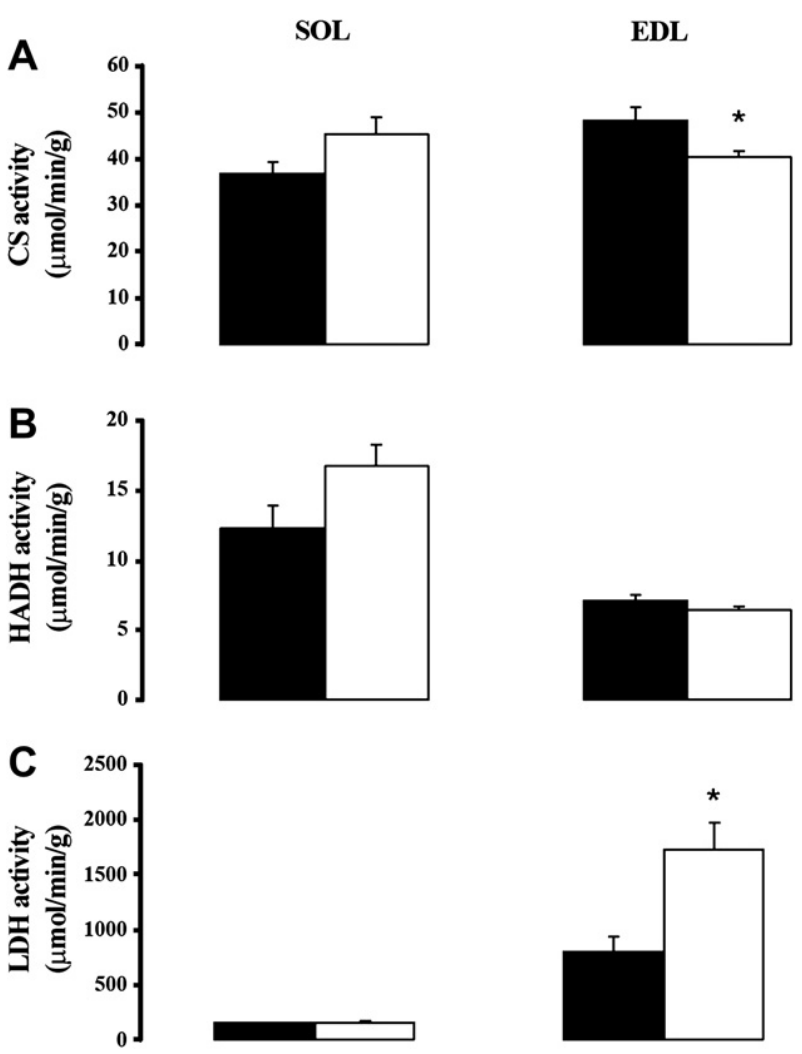

Figure 2. (A) CS activity in oxidative muscle: soleus (SOL) and glycolytic muscle: extensor digitorum longus (EDL) in sham-exposed $(\square ; n=6$ ) and SMF exposed rats ( $\square ; n=6$ ); (B) HADH activity and (C) LDH activity. Values are mean \pm SEM. $* p<0.05$ vs. sham-exposed rats. 
reduced and lactate is used as a metabolic substrate $(31,32)$. This metabolic switch is often described in glucose homeostasis disorders such as diabetes (33-35) and our exposed rats also displayed lower plasma insulin levels, which could further favor the decrease in glucose uptake. Insulin levels were not different in fasted SMF-exposed rats and controls and also during glucose tolerance tests in the two groups. The reason for such a discrepancy between fasting and postprandial insulin levels (changes in insulin degradation and/or secretion) remains to be determined. SMF exposure has been shown to have an impact on impact on insulin secretion. Sakurai et al. (36) found an increase in insulin secretion after SMF exposure and, on the other hand, on isolated pancreatic islets, Hayek et al. (37) demonstrated a decrease in insulin secretion after SMF exposure. These alterations in insulin secretion may be due to the increase in reactive oxygen species (ROS), which are suggested to be important mediators of SMF effects (38).

Skeletal muscle is the main producer and consumer of lactate (39-41). The increase in LDH activity and the decrease in CS activity were observed only in glycolytic muscles. These data indicate that glycolytic muscles participate actively in the increase of plasma lactate under our conditions and emphasize the importance of muscle typology in metabolic responses.

Finally, we also found that after SMF exposure, glycerol, cholesterol and phospholipid contents were significantly increased in the plasma, whereas triglycerides remained unchanged. An excess of circulating lipids is often associated with cardiovascular diseases and glucose metabolism deregulation $(42,43)$. Adipose tissue is a likely candidate for the release of such lipids in the circulation because of lipid metabolism alterations. The higher plasma glycerol level in rats exposed to SMFs suggest an increased adipose tissue lipolysis is in accordance with the decreased plasma insulin levels. In addition, increases in circulating cholesterol and phospholipids suggest a higher turnover of plasma membrane constituents. Our results concerning lipid metabolism alterations are in line with the signalling networks identified to respond to SMF exposure by Wang et al. (44). Hashish et al. (45) found in liver a significant increase in lipid peroxidation associated with a decrease in the antioxidant GSH after SMF exposure, suggesting an increase in oxidative stress after such exposure. Alternate magnetic field exposure induces an accumulation of lipids in the plasma membrane of heart associated with a decrease in membrane fluidity (46). Moreover, Rosen et al. (11) suggested that changes to ion channel conductivity due to SMF exposure may result from the slow re-orientation of aligned groups of diamagnetic phospholipid molecules within the cell membrane. Thus, SMF exposure could alter membrane fluidity by changing phospholipids membrane composition and phospholipids properties. Consequently, SMF exposure could modify molecule flux into the cell membrane.
In conclusion, our findings at both systemic and tissue levels produce evidence for an impaired glucose homeostasis and a deregulated lipid metabolism after a moderateintensity SMF exposure (1 h/day) for 15 days. These data question the safety of such exposures. Further investigations are necessary to evaluate long-term consequences of these metabolic alterations and their reversibility.

\section{References}

1. Chen H, Simar D, Lambert K, et al. Maternal and postnatal overnutrition differentially impact appetite regulators and fuel metabolism. Endocrinology 2008;149:5348-5356.

2. Chen H, Simar D, Morris MJ. Hypothalamic neuroendocrine circuitry is programmed by maternal obesity: interaction with postnatal nutritional environment. PLoS One 2009;4:e6259.

3. Lambert K, Py G, Robert E, et al. Does high-sucrose diet alter skeletal muscle and liver mitochondrial respiration? Horm Metab Res 2003;35: 546-550.

4. Havas M. Dirty electricity elevates blood sugar among electrically sensitive diabetics and may explain brittle diabetes. Electromagn Biol Med 2008;27:135-146.

5. Dini L, Abbro L. Bioeffects of moderate-intensity static magnetic fields on cell cultures. Micron 2005;36:195-217.

6. Genuis SJ. Fielding a current idea: exploring the public health impact of electromagnetic radiation. Public Health 2008;122:113-124.

7. Swanson J. Consultation on revisions to the European Directive on occupational EMF exposure. J Radiol Prot 2009;29:291-292.

8. International Commission on Non-Ionizing Radiation Protection. Guidelines on limits of exposure to static magnetic fields. Health Phys 2009;96:504-514.

9. Iteğin M, Günay I, Loğoğlu G, et al. Effects of static magnetic field on specific adenosine-5' -triphosphatase activities and bioelectrical and biomechanical properties in the rat diaphragm muscle. Bioelectromagnetics 1995; 16:147-151.

10. Jajte J, Grzegorczyk J, Zmyślony M, et al. Effect of $7 \mathrm{mT}$ static magnetic field and iron ions on rat lymphocytes: apoptosis, necrosis and free radical processes. Bioelectrochemistry 2002;57:107-111.

11. Rosen AD. Mechanism of action of moderate-intensity static magnetic fields on biological systems. Cell Biochem Biophys 2003;39:163-173.

12. Rosen AD. Effect of a $125 \mathrm{mT}$ static magnetic field on the kinetics of voltage activated $\mathrm{Na}^{+}$channels in $\mathrm{GH} 3$ cells. Bioelectromagnetics 2003;24:517-523.

13. Rosen $\mathrm{AD}$, Chastney EE. Effect of long term exposure to $0.5 \mathrm{~T}$ static magnetic fields on growth and size of GH3 cells. Bioelectromagnetics 2009;30:114-119.

14. Xu S, Okano H, Ohkubo C. Subchronic effects of static magnetic fields on cutaneous microcirculation in rabbits. Vivo 1998;12:383-389.

15. Yuge L, Kataoka K. Differentiation of myoblasts is accelerated in culture in a magnetic field. Vitro Cell Dev Biol Anim 2000;36: 383-386.

16. Morrow AC, Dunstan RH, King BV, et al. Metabolic effects of static magnetic fields on Streptococcus pyogenes. Bioelectromagnetics 2007;28:439-445.

17. Gorczynska E, Wegrzynowicz R. Glucose homeostasis in rats exposed to magnetic fields. Invest Radiol 1991;26:1095-1100.

18. Chater S, Abdelmelek H, Pequignot JM, et al. Effects of sub-acute exposure to static magnetic field on hematologic and biochemical parameters in pregnant rats. Electromagn Biol Med 2006;25:135-144.

19. Coletti D, Teodori L, Albertini MC, et al. Static magnetic fields enhance skeletal muscle differentiation in vitro by improving myoblast alignment. Cytometry A 2007;71:846-856. 
20. Pilla AA, Muehsam DJ, Markov MS, et al. EMF signals and ion/ligand binding kinetics: prediction of bioeffective waveform parameters. Bioelectrochem Bioenerg 1999;48:27-34.

21. Brix G, Strieth S, Strelczyk D, et al. Static magnetic fields affect capillary flow of red blood cells in striated skin muscle. Microcirculation 2008;15:15-26.

22. Xu S, Okano H, Ohkubo C. Acute effects of whole-body exposure to static magnetic fields and $50-\mathrm{Hz}$ electromagnetic fields on muscle microcirculation in anesthetized mice. Bioelectrochemistry 2001;53: 127-135.

23. Pilla AA. Mechanisms and therapeutic applications of time-varying and static magnetic fields. In: Barnes FGB, ed. Handbook of Biological Effects of Electromagnetic Fields. 3rd Ed. Boca Raton: CRC Press; 2006. pp. 351-412.

24. Metz L, Vermaelen M, Lambert K, et al. Endurance training increases lactate transport in male Zucker fa/fa rats. Biochem Biophys Res Commun 2005;331:1338-1345

25. Gutmann I, Wahlefeld M. L-(+)-Lactate Determination with Lactate Dehydrogenase and NAD. New York: Academic Press; 1974.

26. Shibuya I, Honda H, Maruo B. Simplified colorimetry without incineration of phosphorus in phosphatides. Agric Biol Chem 1967;31:111-114

27. Srere P. Citrate synthase. Methods Enzymol 1969;13:3-11.

28. Lo S, Russell JC, Taylor AW. Determination of glycogen in small tissue samples. J Appl Physiol 1970;28:234-236.

29. Abdelmelek H, Molnar A, Servais S, et al. Skeletal muscle HSP72 and norepinephrine response to static magnetic field in rat. J Neural Transm 2006;113:821-827.

30. Miller BF, Fattor JA, Jacobs KA, et al. Lactate and glucose interactions during rest and exercise in men: effect of exogenous lactate infusion. J Physiol 2002;544:963-975.

31. Vettor R, Lombardi AM, Fabris R, et al. Substrate competition and insulin action in animal models. Int $\mathrm{J}$ Obes Relat Metab Disord 2000;24:S22-S24.

32. Lombardi AM, Fabris R, Bassetto F, et al. Hyperlactatemia reduces muscle glucose uptake and GLUT-4 mRNA while increasing (E1alpha) PDH gene expression in rat. Am J Physiol 1999;276:E922-E929.

33. Vettor R, Lombardi AM, Fabris R, et al. Lactate infusion in anesthetized rats produces insulin resistance in heart and skeletal muscles. Metabolism 1997;46:684-690.
34. Py G, Eydoux N, Perez-Martin A, et al. Streptozotocin-induced diabetes decreases rat sarcolemmal lactate transport. Metabolism 2001; 50:418-424.

35. Py G, Lambert K, Milhavet O, et al. Effects of streptozotocin-induced diabetes on markers of skeletal muscle metabolism and monocarboxylate transporter 1 to monocarboxylate transporter 4 transporters Metabolism 2002;51:807-813.

36. Sakurai T, Terashima S, Miyakoshi J. Effects of strong static magnetic fields used in magnetic resonance imaging on insulin-secreting cells. Bioelectromagnetics 2009;30:1-8.

37. Hayek A, Guardian C, Guardian J, et al. Homogeneous magnetic fields influence pancreatic islet function in vitro. Biochem Biophys Res Commun 1984;122:191-196.

38. Okano H. Effects of static magnetic fields in biology: role of free radicals. Front Biosci 2008;13:6106-6125.

39. Bergman BC, Wolfel EE, Butterfield GE, et al. Active muscle and whole body lactate kinetics after endurance training in men. J Appl Physiol 1999;87:1684-1696.

40. Brooks GA. Lactate: link between glycolytic and oxidative metabolism. Sports Med 2007;37:341-343.

41. Hashimoto T, Brooks GA. Mitochondrial lactate oxidation complex and an adaptive role for lactate production. Med Sci Sports Exerc 2008; $40: 486-494$

42. Boden G, Shulman GI. Free fatty acids in obesity and type 2 diabetes: defining their role in the development of insulin resistance and betacell dysfunction. Eur J Clin Invest 2002;32:14-23.

43. Savage DB, Petersen KF, Shulman GI. Disordered lipid metabolism and the pathogenesis of insulin resistance. Physiol Rev 2007;87: 507-520.

44. Wang Z, Sarje A, Che P-L, et al. Moderate strength $(0.23-0.28 \mathrm{~T})$ static magnetic fields (SMF) modulate signaling and differentiation in human embryonic cells. BMC Genomics 2009;10:356-379.

45. Hashish AH, El-Missiry MA, Abdelkader HI, et al. Assessment of biological changes of continuous whole body exposure to static magnetic field and extremely low frequency electromagnetic fields in mice. Ecotoxicol. Environ. Saf 2007;71:895-902.

46. Chernysheva ON. Status of the lipid phase of plasma membranes of the rat heart after repeated exposure to an alternate magnetic field of $50 \mathrm{~Hz}$ frequency. Kosm Biol Aviakosm Med 1990;24:30-31. 